\title{
LETTER IN REPLY
}

For reprint orders, please contact: reprints@futuremedicine.com

\section{Letter in reply: prognostic prediction by liver tissue proteomic profiling in patients with colorectal liver metastases}

Response to: S Sabour. Prognostic prediction by liver tissue proteomic profiling in patients with colorectal liver metastases; rule of thumb. Future Oncol. 13(13), 11331134 (2017).

\section{Adalgiza Reyes', Josep Marti', Santiago Marfa², Wladimiro Jimenez ${ }^{2,3}$, Vedrana Reichenbach², Amalia Pelegrina', Con stantino Fondevila', Juan CG Valdecasas' \& Josep Fuster ${ }^{*}, 1$}

First draft submitted: 27 February 2017; Accepted for publication: 9 March 2017; Published online: 23 June 2017

We thank S Sabour for the interest expressed in our article [1] and we acknowledge his continuous quest to improve the design of predictive studies through several letters to journal editors during the last years, to point out methodological issues, mistakes, misconceptions and misinterpretations [2-4].

The results from our study showed that a single protein peak $(7371 \mathrm{~m} / \mathrm{z})$ could differentiate colorectal liver metastases patients from control patients with a sensitivity of $94.1 \%$ and a specificity of $100 \%$. Also, with regard to colorectal liver metastases patients prognosis after surgery, we found that the algorithm that best differentiated favorable and unfavorable groups only needed two protein peaks ( 2970 and $2871 \mathrm{~m} / \mathrm{z}$ ) to discern prognosis with a sensitivity of $100 \%$ and a specificity of $90 \%$. These promising results, which S Sabour seems to minimize, come from a preliminary study, are not at all clinically definitive (i.e., validated) and should thus encourage further validation studies as we clearly wrote in the 'Discussion'. We were fully aware of these design limitations from the initial moment we designed the study and that was the reason to necessarily include some words of caution in the 'Discussion'. Moreover, among other reasons for this prudent statement we can include that some preliminary studies can give misleading results without validation of the initial prediction (as $S$ Sabour rightly points out) but also because validation studies (and not exploratory or preliminary studies like ours) are the ones that have the power to ascertain the strength of the relation and properly study the interaction between variables.

\section{Disclaimer}

The opinions expressed in this interview are those of the interviewees and do not necessarily reflect the views of Future Medicine Ltd.

Financial \& competing interests disclosure

The original paper referred to in this letter to the editor was supported by grants from Dirección General de Investigación Cientifica y Técnica (SAF 2012-35979 to W Jiménez and BES-2010-035452 to S Marfa) and from the Agència de Gestió d'Ajuts Universitaris i de Recerca (SGR 2009/1496). CIBEREHD is funded by the Instituto de Salud Carlos III. This work is cofinanced by the EU through the European Regional Development Fund (ERDF) 'A way of making 


\section{LETTER IN REPLY Reyes, Marti, Marfa et al.}

Europe'. The Association 'Llavaneres contra el Càncer' supported the work of J Fuster. The authors have no other relevant affiliations or financial involvement with any organization or entity with a financial interest in or financial conflict with the subject matter or materials discussed in the manuscript. This includes employment, consultancies, honoraria, stock ownership or options, expert testimony, grants or patents received or pending, or royalties.

No writing assistance was utilized in the production of this manuscript.

\section{References}

1 Reyes A, Marti J, Marfà S et al. Prognostic prediction by liver tissue proteomic profiling in patients with colorectal liver metastases. Future Oncol. 13(10), 875-882 (2017).

2 Sabour S. Tissue marker clip placement after 11-gauge vacuum-assisted stereotactic breast biopsy: methodological issue on validity and reliability. Breast Cancer doi:10.1007/ s12282-017-0755-2 (2017) (Epub ahead of print).

3 Sabour S, Ghassemi F. Submaximal step tests to estimate maximal oxygen uptake in healthy adults: methodological issues about validity and reliability. Sports Med. 46(9), 1381-1382 (2016).
4 Sabour S. Development of prediction tools for diarrhea and rash in breast cancer patients receiving lapatinib in combination with capecitabine: rule of thumb in prediction studies. Breast Cancer Res. Treat. 148(2), 465 (2014). 